\title{
Effects of Moral Hazard and Private Information on Investment Timing: an Auction Model
}

\author{
Jøril Mæland \\ Norwegian School of Economics and Business Administration
}

April, 2006

JEL Classifications: G31, D82, D44

Keywords: real options, private information, hidden effort, agency cost, investment timing

Norwegian School of Economics and Business Administration, Department of Finance and Management Science, Helleveien 30, N-5045 Bergen, Norway.

Phone: +47 559593 13. E-mail: joril.maeland@nhh.no. 


\begin{abstract}
This paper analyzes investment timing in the presence of agency conflicts and information asymmetries. It is assumed that an owner of an investment project (a real option) needs specialized expertise in order to make the investment. There are $n$ firms with the required knowledge, and these "expert firms" compete about a contract that gives the contract winner the right to manage the investment. Each competitor chooses an unobserved effort that influences the probability of its investment cost level. When effort is made, each expert firm privately observes its own investment costs, but not the competitors'. The winner of the contract is the firm that (truthfully) reports the lowest investment cost.

The private information problem increases the critical price of investment compared to the case of no inefficiency. When moral hazard is included in the model, the effect on the trigger value is ambiguous for $n>1$. In the case in which there is one expert firm $(n=1)$, the moral hazard problem always mitigates the inefficiency cost due to private information. The last result is consistent with findings in Grenadier and Wang (2005).
\end{abstract}




\section{Introduction}

Over the last decade, real options theory has made its way into standard textbooks on corporate finance, as well as textbooks on derivatives and risk management. This reflects the increasing importance of the real options framework as a tool for making investment decisions in corporations.

The standard real options approach does not take into account agency issues in project evaluation, although there often are private information problems and hidden action conflicts inherent in project decisions. Such "inefficiencies" reduce project values of owners, and change optimal investment strategies of real options. Agency problems in combination with real options are studied in this paper.

The setting is a firm that considers to invest in a project, but needs to rely on a supplier of some technological solutions in order to make the investment. Examples of such investments are a firm's adoption of technological innovations, an oil company needing some equipment in order to produce oil, and a firm that needs construction services in order to build a new building. Typically, all these investments require specialized expertise, implying that suppliers of products and services may have private information and exert hidden effort that influence costs of the investments.

In the model it is assumed that there are several potential suppliers of technical solutions, and that each of these "expert firms" will have private information about their respective costs of exercising the real option. Each expert firm observes its investment cost level after it has made an effort. The effort affects the probability of the investment cost level: an increase in effort increases the probability of a low investment cost level.

The project owner aims to contract with the expert firm that maximizes the project owner's value. This optimization problem is solved using a private values auction model.

We find that private information increases the critical project value of investment, compared to the benchmark case of no incentive problems. When we have both types of incentive problems simultaneously, hidden effort mitigates the under-investment problem caused by private information for a subinterval of possible investment cost levels. However, numerical 
examples indicate that for high investment cost levels, the hidden effort problem enlarges the under-investment effect. Only in the case in which we have one firm with private information and hidden effort, does the hidden effort problem mitigate the under-investment effect for all investment cost levels.

We do not take into account that the project owner may choose the number of expert firms to participate in the auction. However, numerical examples of the model indicates a trade-off of how many firms to invite to submit bids: The more firms that submits bids, the higher is the competition, and the lower is the cost of exercising to option to invest. On the other hand, the more firms that submit bids, the higher is the owner's cost of giving the firms incentives to choose high effort, leading to rent dissipation.

In Grenadier and Wang (2005) a similar problem is analyzed for the case in which there is only one party with private information and agency problems. This is a natural restriction in their setting, as they study the situation where shareholders delegate an investment decision to a manager with private information, and who influence the investment project by an unobservable action. Grenadier and Wang (2005) finds that private information leads to under-investment (i.e., the critical value for investment increases compared to the case of no private information), whereas hidden effort mitigates this effect on the critical value. These results are consistent with the results of the model below for the special case in which one firm only has private information and hidden effort (i.e., when $n=1$ ).

The model presented in this paper builds on Mæland (2002, 2005): a real option owner needs an expert to make the investment decision, and the expert has private information about the (constant) cost of investing in the project. In these papers moral hazard problems are not included. Similarly to Grenadier and Wang (2005), Mæland (2002, 2005) finds that the critical value of the investment project increases due to private information.

Other papers that combine agency conflicts with real options include Bjerksund and Stensland (2000), Moel and Tufano (2000), and Antle, Bogetoft, and Stark (2001).

The rest of the paper is outlined as follows: In section 2 uncertain future cash flows are evaluated, and a benchmark case of symmetric information and no agency issues is presented. The auction model is formulated and the results are discussed in section 3. Section 4 gives 
some concluding remarks.

\section{Evaluation of future cash flows: A first-best benchmark}

It is assumed that a firm has an opportunity to invest in a project, where the investment opportunity can be formulated as a perpetual American call option: by paying an investment cost the firm obtains the market value of the net future cash flows from the completed project. Under a risk neutral probability measure, the market value of the project when the investment is made, $S_{t}$, is given by the stochastic process

$$
d S_{t}=(r-\delta) S_{t} d t+\sigma S_{t} d B_{t}, \quad s=S_{0}
$$

In equation (1), $r$ is a constant risk-free interest rate per year, $\delta$ denotes a constant convenience yield per year, $\sigma$ is the yearly volatility, and $B_{t}$ is a Wiener process. The value of the completed project, $S_{t}$, is often referred to as "the value of the asset in place" (McDonald and Siegel (1986)).

In the benchmark case we assume that the real option owner observes the respective investment cost levels of the expert firms, and that the owner enters into a contract with the expert with the lowest investment cost, denoted $K^{L}$. Let $E\left[\cdot \mid \mathcal{F}_{t}\right]$ denote the expectation under a risk neutral probability measure conditional on the information at date $t, \mathcal{F}_{t}$. As the expert's profit from managing the investment cost is zero in absence of agency costs, the owner's optimization problem is

$$
V^{F B}\left(s ; K^{L}\right)=\sup _{\tau} E\left[e^{-r \tau}\left(S_{\tau}-K^{L}\right)^{+} \mid \mathcal{F}_{0}\right]
$$

where $\tau$ is a stopping time.

The investment opportunity in equation (2) is formulated as a perpetual option. Timehomogeneity implies that the present value operator $E\left[e^{-r \tau} \mid \mathcal{F}_{t}\right]$ can be formulated as a function

of the asset value, $s$, and a critical value for investment, $\hat{S}\left(K^{L}\right)$. Define $D\left(s ; \hat{S}\left(K^{L}\right)\right)=$ $E\left[e^{-r \tau} \mid \mathcal{F}_{t}\right]$. The corresponding ordinary equation equals

$$
\frac{1}{2} \sigma^{2} s^{2} D_{s s}+(r-\delta) s D_{s}-r D=0
$$


with boundary conditions $\lim _{s \uparrow \hat{S}} D(\hat{S})=1$ and $\lim _{s \downarrow 0} D(0)=0$. The solution of the ordinary differential equation is given by

$$
D\left(s ; \hat{S}\left(K^{L}\right)\right)= \begin{cases}\left(\frac{s}{\hat{S}\left(K^{L}\right)}\right)^{\beta} & \text { when } s<\hat{S}\left(K^{L}\right) \\ 1 & \text { when } s \geq \hat{S}\left(K^{L}\right)\end{cases}
$$

The function $D\left(s ; \hat{S}\left(K^{L}\right)\right)$ is interpreted as the present value of one unit of money received at the first moment when the asset value reaches $\hat{S}\left(K^{L}\right)$.

Using the result in equation (4), the real option owner's optimization problem in equation (2) is obtained as,

$$
V^{F B}\left(s ; K^{L}\right)= \begin{cases}\left(\frac{s}{S^{*}\left(K^{L}\right)}\right)^{\beta}\left(S^{*}\left(K^{L}\right)-K^{L}\right) & \text { for } s<S^{*}\left(K^{L}\right) \\ s-K^{L} & \text { for } s \geq S^{*}\left(K^{L}\right)\end{cases}
$$

where the optimal trigger value, $S^{*}\left(K^{L}\right)$, equals

$$
S^{*}\left(K^{L}\right)=\frac{\beta}{\beta-1} K^{L}
$$

and

$$
\beta=\frac{1}{\sigma^{2}}\left[\frac{\sigma^{2}}{2}-(r-\delta)+\sqrt{\left(r-\delta-\frac{\sigma^{2}}{2}\right)^{2}+2 r \sigma^{2}}\right]>1 .
$$

Equation (5) shows that the project owner's value when immediate investment is the optimal decision, is given by the value of the completed project, $s$, reduced by the investment $\operatorname{cost} K^{L}$. When waiting is the optimal strategy, the owner's value equals the present value of the critical price for investment, $S^{*}\left(K^{L}\right)$, minus the investment cost. The solution in (5)-(7) is analogous to the solution of a perpetual American call option under the assumption that the underlying asset follows a geometric Brownian motion process. It also equals the real option values in McDonald and Siegel (1986), Dixit (1989), and Bjerksund and Ekern (1990), among others.

Note that the project value $V^{F B}\left(s ; K^{L}\right)$ is based on ex post information, i.e., it is assumed the option owner observes the investment cost $K^{L}$. The value of the project given ex ante 


$\begin{aligned} & \text { Ex ante information: } \\ & \text { the } n \text { firms do not know } \\ & \text { their respective investment } \\ & \text { cost levels }\end{aligned}$
$\begin{aligned} & \text { The project owner } \\ & \text { announces an } \\ & \text { auction. }\end{aligned}$ $\begin{aligned} & \begin{array}{l}\text { Ex post information: } \\ \text { the } n \text { firms observe their } \\ \text { respective investment cost } \\ \text { levels } n \text { firms choose } \\ \text { an effort level, in } \\ \text { order to get to know } \\ \text { their respective } \\ \text { investment cost } \\ \text { levels, and in order } \\ \text { to choose the } \\ \text { optimal effort level. }\end{array} \\ & \begin{array}{l}\text { simultaneously } \\ \text { report their } \\ \text { respective } \\ \text { investment cost } \\ \text { levels (submit bids). } \\ \text { The winner of the } \\ \text { contract is chosen } \\ \text { based on the reports }\end{array}\end{aligned}$

Figure 1: The stages of the model.

information, i.e., before the project owner observes the investment cost, equals

$$
\int_{\underline{K}}^{\bar{K}} V^{F B}\left(s ; K^{L}\right) f^{H}\left(K^{L}\right) d K^{L},
$$

where $f^{H}\left(K^{L}\right)$ is the probability density of the investment cost, and $\underline{K}$ and $\bar{K}$ are the lower and upper limits of the investment cost.

\section{The auction model}

\subsection{Economic setting}

We now turn to the investment problem under the assumption that there are $n$ firms with the required expertise to contract with the project owner. The stages of the model are shown in figure 1.

The project owner organizes an auction in order to contract with the expert firm that maximizes the owner's investment opportunity. The two incentive problems, hidden effort and 
private information, are in the model included as follows: Ex ante each firm $i$ makes an effort. Effort is costly, but a high effort increases the probability of being a "low-cost" type. Ex post, i.e., when an effort is made, firm $i$ observes its cost, $K_{i}$, of making the investment. Each firm reports an investment cost, $\hat{K}_{i} \in[\underline{K}, \bar{K}]$, to the project owner. The vector of reported investment cost levels is represented by $\hat{K}=\left[\hat{K}_{1}, \hat{K}_{2}, \ldots, \hat{K}_{n}\right]$.

The project owner's optimization problem is solved using a second-price sealed-bid privatevalues auction ${ }^{1}$. However, by the revenue equivalence theorem ${ }^{2}$, it can be shown that under our assumptions (i.e., that the contract goes to the bidder with the best bid, and any bidder with the worst bid expect zero surplus) the results do not depend on the organization of the auction. Thus, in our model, the winner of the contract is the firm that reports the lowest investment cost.

For simplicity, we assume that the firms can choose between only to effort levels, high effort or low effort. The cost of exerting high effort is $\xi$, whereas the cost of low effort is (without loss of generalization) zero.

The project owner's incentive scheme is based on the reported investment cost levels, $\hat{K}$. Let $y_{i}(\hat{K})$ be a control variable by which the project owner chooses the winner of the contract, i.e., $y_{i}$ equals 1 if firm $i$ wins the contract, and is zero otherwise. Firm $i$ 's expected compensation by participating in the auction is given by $w_{i}(\hat{K})$, and the investment strategy (the stopping time) is denoted $\tau_{i}(\hat{K})$. Thus, the project owner's incentive scheme is given by $\left\{y_{i}(\hat{K}), w_{i}(\hat{K}), \tau_{i}(\hat{K})\right\}$.

In the presentation below it is assumed that the asset value at time $0, s$, always is lower than the critical value of investment $S_{i}$. This is without loss of generalization, and simplifies the presentation of the model. Firm $i$ 's value based on information after the firm has observed its cost level (i.e., based on ex post information), is given by

$$
v_{i}\left(s, K_{i} ; \hat{K}_{i}\right)=E^{H, K_{i}}\left[\left(\frac{s}{S_{i}(\hat{K})}\right)^{\beta}\left(w_{i}(\hat{K})+y_{i}(\hat{K})\left(\hat{K}_{i}-K_{i}\right)\right)\right] .
$$

\footnotetext{
${ }^{1}$ As the name of the auction indicates, in such an auction, each bidder simultaneously submits a bid, without seeing others' bids, the contract is given to the bidder who makes the best bid, the contract is priced according to the second-best bidder, and truth-telling is a dominant strategy. This type of auction is also called a Vickrey auction. For a survey of auction theory, see Klemperer (1999).

${ }^{2}$ The revenue equivalence theorem was first shown by Myerson (1981) and Riley and Samuelson (1981).
} 
The superscript $K_{i}$ in the expectation operator $E^{H, K_{i}}[\cdot]$ indicates that firm $i$ observes its own investment cost, but not the other firms' respective investment cost level. The superscript $H$ states that the expectation is taken under the choice of high effort. Each firm $i$ optimizes its value function in (9) with respect to the report $\hat{K}_{i}$. Equation (9) shows that firm $i$ 's value equals the present value of the compensation, transferred at the time of investment, and the present value of the difference between the reported investment cost and the true investment cost, adjusted by the probability of being the winner of the contract. Thus, if firm $i$ wins the contract (in which case $y_{i}=1$ ) the project owner at the time of investment transfers the compensation $w_{i}$, as well as the reported investment cost $\hat{K}_{i}$, to the contract winner. The contract winner's value at the investment time is reduced by its true cost of making the investment, $K_{i}$.

We restrict the set of incentive schemes, or contracts, to the set of truthful contracts. This simplifies the project owner's optimization problem, and is done without loss of generalization ${ }^{3}$. Given truth telling constraints, the first- and second-order conditions for optimization of firm $i$ 's value equal

$$
\left.\frac{\partial v_{i}\left(s, K_{i} ; \hat{K}_{i}\right)}{\partial \hat{K}_{i}}\right|_{\hat{K}_{i}=K_{i}}=0
$$

and

$$
\left.\frac{\partial^{2} v_{i}\left(s, K_{i} ; \hat{K}_{i}\right)}{\partial \hat{K}_{i}^{2}}\right|_{\hat{K}_{i}=K_{i}} \leq 0
$$

respectively.

Evaluation of the first-order condition leads to

$$
\frac{d v_{i}\left(s, K_{i}\right)}{d K_{i}}=E^{H, K_{i}}\left[\left(\frac{s}{S_{i}(K)}\right)^{\beta} y_{i}(K) \mid \mathcal{F}_{0}^{K_{i}}\right]
$$

The project owner's value function can be formulated as

$$
v^{O}\left(s ; S_{i}(K), y_{i}(K), w_{i}(K)\right)=E\left[\sum_{i=1}^{n}\left\{\left(\frac{s}{S_{i}\left(K_{i}\right)}\right)^{\beta}\left(S_{i}(K)-K_{i}\right) y_{i}(K)-V_{i}\left(s ; K_{i}\right)\right\}\right],
$$

\footnotetext{
${ }^{3}$ For references on the revelation principle, see for instance Baron and Myerson (1982) and Laffont and Tirole (1993).
} 
where the expectation operator $E[\cdot]$ represents the expectation based on the project owner's ex ante information (i.e., the owner's information before the owner has received the cost reports from the $n$ firms). Recall that $y_{i}=1$ if firm $i$ wins the contract, and zero otherwise. Thus, the first term inside the brackets of equation (13) is the value of the project given that firm $i$ wins the contract, and zero otherwise. This term is summed over all the $n$ firms. The project owner's value is reduced by the present values of the compensations to the $n$ firms, as shown by the second term inside the brackets. Under truthful contracts, each firm $i$ 's value is the discounted value of the expected compensation, i.e.,

$$
V_{i}\left(s ; K_{i}\right)=E^{H, K_{i}}\left[\left(\frac{s}{S_{i}(K)}\right)^{\beta} w_{i}\left(K_{i}\right)\right]
$$

Firm $i$ 's value may be interpreted as its value of private information.

Note that in equation (13) the control variable with respect to firm $i, S_{i}(K)$, depends on all the (truthfully) reported investment cost levels, not only on firm $i$ 's own cost level. However, it can be shown that firm $i$ 's critical price for investment in optimum depends on its own investment cost, $K_{i}$, only. This result is based on an analogous result in Laffont and Tirole (1987).

Thus, the project owner's value function can be simplified to

$$
\hat{v}^{O}\left(s ; S_{i}\left(K_{i}\right), Y_{i}^{H}\left(K_{i}\right)\right)=\sum_{i=1}^{n} \int_{\underline{K}}^{\bar{K}}\left[\left(\frac{s}{S_{i}\left(K_{i}\right)}\right)^{\beta}\left(S_{i}\left(K_{i}\right)-K_{i}\right) Y_{i}^{H}\left(K_{i}\right)-V_{i}\left(K_{i}\right)\right] f^{H}\left(K_{i}\right) d K_{i},
$$

where $Y_{i}^{H}\left(K_{i}\right)$ is firm $i$ 's probability of winning the contract, i.e., $Y_{i}^{H}\left(K_{i}\right) \equiv E^{H, K_{i}}\left[y_{i}(K)\right]$.

We interpret $f^{H}\left(K_{i}\right)$ as the probability density when high effort is chosen. The corresponding cumulative distribution is given by $F^{H}\left(K_{i}\right)=\int_{\underline{K}}^{K_{i}} f^{H}(x) d x$. Analogously, the probability density and the distribution function of low effort are $f^{L}\left(K_{i}\right)$ and $F^{L}\left(K_{i}\right)$, respectively. The probability distributions are assumed to be absolutely continuous, common knowledge, and the fraction $F^{j}\left(K_{i}\right) / f^{j}\left(K_{i}\right)$ is non-decreasing, $j=\{L, H\}$. As high effort increases the probability of a low investment cost, we need the condition $F^{H}\left(K_{i}\right) \geq F^{L}\left(K_{i}\right)$. Firm $i$ 's probability of being the contract winner given effort level $j=\{L, H\}, Y_{i}^{j}$, equals the probability that firm $i$ 
has the lowest cost is in a sample of $n$ firms, i.e., $Y_{i}^{j}\left(K_{i}\right)=\left[1-F^{j}\left(K_{i}\right)\right]^{n-1}$.

By partial integration and equation (12), the ex ante value of firm $i$ when it chooses to exert effort level $j, j \in[L, H]$, can be formulated as

$$
\int_{\underline{K}}^{\bar{K}} V_{i}\left(s ; K_{i}\right) f^{j}\left(K_{i}\right) d K_{i}=\int_{\underline{K}}^{\bar{K}}\left(\frac{s}{S_{i}\left(K_{i}\right)}\right)^{\beta} Y^{j}\left(K_{i}\right) F^{j}\left(K_{i}\right) d K_{i} .
$$

\subsection{The optimization problem}

By the simplifications above we can now formulate the project owner's main optimization problem: for each firm $i$ from 1 to $n$,

$$
\sup _{S_{i}\left(K_{i}\right)} \int_{\underline{K}}^{\bar{K}}\left[\left(\frac{s}{S_{i}\left(K_{i}\right)}\right)^{\beta}\left(S_{i}\left(K_{i}\right)-K_{i}\right) Y_{i}^{H}\left(K_{i}\right)-V_{i}\left(s, K_{i}\right)\right] f^{H}\left(K_{i}\right) d K_{i},
$$

subject to the four restrictions,

(i) The ex post incentive constraint (private information),

$$
\frac{d V_{i}\left(s, K_{i}\right)}{d K_{i}}=-\left(\frac{s}{S_{i}\left(K_{i}\right)}\right)^{\beta} Y_{i}^{H}\left(K_{i}\right) \text { for any } K_{i} \in[\underline{K}, \bar{K}],
$$

(ii) the ex post participation constraint,

$$
V_{i}\left(s, K_{i}\right) \geq 0 \text { for any } K_{i} \in[\underline{K}, \bar{K}]
$$

(iii) the ex ante incentive constraint (moral hazard),

$$
\int_{\underline{K}}^{\bar{K}}\left(\frac{s}{S_{i}\left(K_{i}\right)}\right)^{\beta}\left(Y_{i}^{H}\left(K_{i}\right) F^{H}\left(K_{i}\right)-Y_{i}^{L}\left(K_{i}\right) F^{L}\left(K_{i}\right)\right) d K_{i} \geq \xi,
$$

and

(iv) the ex ante participation constraint,

$$
\int_{\underline{K}}^{\bar{K}}\left(\frac{s}{S_{i}\left(K_{i}\right)}\right)^{\beta} Y_{i}^{H}\left(K_{i}\right) F^{H}\left(K_{i}\right) d K_{i} \geq 0 .
$$


Note that the optimization implicitly presupposes that it is always optimal to give the expert firms an incentive to exert high effort. This assumption is made as this is the interesting situation to analyze, i.e., the case where the two incentive problems interact.

The truth telling constraint in (17) is derived using equation (12). The ex post participation constraint in equation (18) states that each firm's value must be positive, as it otherwise will choose not to participate in the auction. The ex ante incentive constraint in (19) says that firm

$i$ 's value of choosing high effort, $\int_{\underline{K}}^{\bar{K}}\left(\frac{s}{S_{i}\left(K_{i}\right)}\right)^{\beta} Y_{i}^{H}\left(K_{i}\right) F^{H}\left(K_{i}\right) d K_{i}-\xi$, must be higher than its value of low effort, $\int_{\underline{K}}^{\bar{K}}\left(\frac{s}{S_{i}\left(K_{i}\right)}\right)^{\beta} Y_{i}^{L}\left(K_{i}\right) F^{L}\left(K_{i}\right) d K_{i}$. The ex ante participation constraint in equation (20) is never binding, because the inequality is satisfied as long as the ex ante incentive constraint is fulfilled, as the cost of high effort, $\xi$, is positive.

\subsection{The optimal investment strategy}

When the effort cost $\xi$ is too low for the ex ante incentive constraint in (19) to bind, the optimal investment strategy is given by

$$
S_{i}^{I}\left(K_{i}\right)=\frac{\beta}{\beta-1}\left(K_{i}+\frac{F^{H}\left(K_{i}\right)}{f^{H}\left(K_{i}\right)}\right) .
$$

The optimal critical price for investment is higher under private information than full information, thus implying under-investment with respect to the timing of the investment. The fraction $F^{H}\left(K_{i}\right) / f^{H}\left(K_{i}\right)$ is interpreted as an inefficiency cost due to private information. We observe that in the case of private information only, the optimal investment strategy does not depend on the number of firms with private information.

When both incentive constraints bind, the solution of the optimization problem implies the optimal critical price for investment is equals

$$
S_{i}^{A I}\left(K_{i}\right)=\frac{\beta}{\beta-1}\left(K_{i}+\frac{F^{H}\left(K_{i}\right)}{f^{H}\left(K_{i}\right)}-\lambda\left(\frac{F^{H}\left(K_{i}\right)}{f^{H}\left(K_{i}\right)}-\frac{Y_{i}^{L}\left(K_{i}\right)}{Y_{i}^{H}\left(K_{i}\right)} \frac{F^{L}\left(K_{i}\right)}{f^{H}\left(K_{i}\right)}\right)\right),
$$

where $\lambda$ is a positive Lagrangian multiplier. The Lagrangian multiplier $\lambda$ is given by the 
equality

$$
\int_{\underline{K}}^{\bar{K}}\left(\frac{s}{S_{i}^{A I}\left(K_{i}\right)}\right)^{\beta}\left(Y_{i}^{H}\left(K_{i}\right) F^{H}\left(K_{i}\right)-Y_{i}^{L}\left(K_{i}\right) F^{L}\left(K_{i}\right)\right) d K_{i}=\xi .
$$

Note that the second-order condition for truth telling in (11) implies that the inequality

$$
\frac{\beta \frac{\partial S_{i}\left(K_{i}\right)}{\partial K_{i}} Y_{i}^{H}\left(K_{i}\right)}{S_{i}\left(K_{i}\right)}-\frac{\partial Y_{i}^{H}\left(K_{i}\right)}{\partial K_{i}} \geq 0
$$

must be satisfied (a[n incomplete] sketch of the proof is shown in appendix A.1). As the last term is negative, the condition in (24) will always be satisfied if $\frac{\partial S_{i}\left(K_{i}\right)}{\partial K_{i}}$ is positive. This means that the truth telling condition is satisfied in the case where private information is the only binding incentive constraint, as $S_{i}^{I}\left(K_{i}\right)$ is increasing in the investment cost $K_{i}$. When both incentive constraints bind, satisfying restrictions for the second-order truth telling condition to hold, are that the fraction $F^{L}\left(K_{i}\right) / f^{H}\left(K_{i}\right)$ is increasing in $K_{i}, f^{H}\left(K_{i}\right) \geq f^{L}\left(K_{i}\right)$, and $\lambda \leq 1$. These conditions ensure that the optimal investment strategy $S_{i}^{A I}$ increases in $K_{i}$, shown in appendix A.2. The restriction on the Lagrangian multiplier $\lambda$ implies that the effort cost $\xi$ cannot be "too high", as implicit differentiation of (23) shows that $d \lambda / d \xi>0$.

As opposed to the optimal investment strategy when only private information is a binding incentive constraint, equation (22) shows that when both constraints bind the optimal investment strategy depends on the number of expert firms, $n$, through dependence of $n$ on $Y_{i}^{L}$ and $Y_{i}^{H}$. For $n>1$, we do not know in general whether the moral hazard problem mitigates the private information effect on the critical price for investment, or whether it further increases the inefficiency problem: the affluence of the effort cost on the optimal investment strategy depends on the relationship,

$$
\frac{d S_{i}^{A I}\left(K_{i}\right)}{d \xi}=\left\{\begin{array}{cl}
<0 & \text { if } \frac{F^{H}\left(K_{i}\right)}{f^{H}\left(K_{i}\right)}-\frac{Y_{i}^{L}\left(K_{i}\right)}{Y_{i}^{H}\left(K_{i}\right)} \frac{F^{L}\left(K_{i}\right)}{f^{H}\left(K_{i}\right)}>0 \\
>0 & \text { if } \frac{F^{H}\left(K_{i}\right)}{f^{H}\left(K_{i}\right)}-\frac{Y_{i}^{L}\left(K_{i}\right)}{Y_{i}^{H}\left(K_{i}\right)} \frac{F^{L}\left(K_{i}\right)}{f^{H}\left(K_{i}\right)}<0
\end{array} .\right.
$$

The expression of $d S_{i}^{A I}\left(K_{i}\right) / d \xi$ is presented in appendix A.3.

In the case where there is only one firm with private information, and both incentive constraints bind simultaneously, the hidden action problem reduces the private information 
problem on the critical price for investment. This is an analogous case to Grenadier and Wang (2005).

\subsection{Implementation of the contract}

Firm $i$ 's ex post value of participating in the auction is given by

$$
V_{i}\left(s, K_{i}\right)=\int_{K_{i}}^{\bar{K}}\left(\frac{s}{S_{i}^{J}(u)}\right)^{\beta} Y_{i}^{H}(u) d u
$$

where $J=\{I, A I\}$. Firm $i$ 's expected compensation given an optimal investment strategy is represented by $w_{i}^{*}\left(K_{i}\right)$. The expected compensation $w_{i}^{*}\left(K_{i}\right)$ is derived by equations (14) and $(26)$,

$$
w_{i}^{*}\left(K_{i}\right)=\int_{K_{i}}^{\bar{K}}\left(\frac{S_{i}^{J}\left(K_{i}\right)}{S_{i}^{J}(u)}\right)^{\beta} Y_{i}^{H}(u) d u .
$$

Note that the compensation function $w_{i}^{*}\left(K_{i}\right)$ is an expected compensation, adjusted for the probability of winning the contract managing the investment of the project. The compensation of the contract winner, denoted $\tilde{w}_{i}(K), K=\left[K_{1}, K_{2}, \ldots, K_{n}\right]$, can be found by evaluation of $E^{H, K_{i}}\left[w_{i}^{*}(K) y_{i}^{*}\left(K_{i}\right)\right]$, where the optimal control variable is given by

$$
y_{i}^{*}\left(K_{i}\right)=\left\{\begin{array}{ll}
1 & \text { if } K_{i}<\min _{j \neq i} K_{j} \\
0 & \text { if } K_{i}>\min _{j \neq i} K_{j}
\end{array} .\right.
$$

Equation (28) states that the firm with the lowest investment cost wins the contract. If $K_{i}=\min _{j \neq i} K_{j}$, the project owner is indifferent between which firm to choose as the winner of the contract. The contract winner's compensation equals

$$
\tilde{w}_{i}(K)=\int_{K_{i}}^{K_{j}}\left(\frac{S_{i}^{J}\left(K_{i}\right)}{S_{i}^{J}(u)}\right)^{\beta} d u
$$

Hence, the contract winner's compensation depends on the investment cost level of the firm with the second-lowest cost report. 


\section{Concluding remarks}

In this paper interactions of private information, moral hazard and competition are studied for an investment in a project. The investment decision is formulated as a standard real option problem of finding the optimal time to invest in the project.

Private information and moral hazard problems are included in the model by assuming that the real option owner needs specialized expertise in order to make the investment. There are $n \geq 1$ expert firms that compete about the contract of managing the investment. The competitors make ex ante an unobservable effort. A higher effort implies a higher probability of realizing a lower investment cost level. After making an effort, each expert firm privately observes their own investment cost.

We find that private information increases the critical price of investment compared to a benchmark without private information. The additional effect of a binding moral hazard problem is ambiguous for when the number of expert firms is larger than one. For a large interval of possible investment cost levels the moral hazard conflict mitigates the private information problem. However, for high intervals of investment cost levels, the moral hazard problem increases the inefficiency in the optimal investment strategy, i.e., the critical price of investment increases more. Only for the case in which $n=1$ does the hidden action problem reduce the inefficiency for all levels of $K_{i}$. This result is consistent with Grenadier and Wang (2005).

The model of this paper is not optimized with respect to the number of expert firms, $n$, participating in the auction. However, numerical examples indicate that a choice of an optimal $n$ is a trade-off: The more firms with private information, the lower is the value of private information, which increases the project owner's value. In addition, a high number of experts means that the contract winner's cost in probability is lower. On the other hand, a large number of participants in the auction implies that the total effort costs are higher, which may lead to higher compensation to the contract winner. 


\section{A Appendix}

\section{A.1 A sketch of the proof of the second-order truth telling condition in equation (24)}

Given that the optimal investment strategy of firm $i$ is found to depend on its own investment cost only, and not its competitors', firm i's value function in equation (9) can be reformulated to

$$
\hat{v}_{i}\left(s, K_{i} ; \hat{K}_{i}\right)=\left(\frac{s}{S_{i}\left(K_{i}\right)}\right)^{\beta}\left(w_{i}\left(\hat{K}_{i}\right)+Y_{i}^{H}\left(\hat{K}_{i}\right)\left(\hat{K}_{i}-K_{i}\right)\right) .
$$

The second-order condition $\partial \hat{v}_{i}\left(s, K_{i} ; \hat{K}_{i}\right) / d \hat{K}_{i} \leq 0$ for $\hat{K}_{i}=K_{i}$ is simplified by differentiating the first-order condition with respect to $K_{i}$, and substitute the result of the differentiation into the second-order condition. This leads to the result in equation (24).

\section{A.2 Differentiation of the optimal investment strategy $S_{i}^{A I}\left(K_{i}\right)$ with respect to firm $i$ 's investment cost $K_{i}$}

Differentiating equation (22) with respect to $K_{i}$ leads to

$$
\frac{d S_{i}^{A I}\left(K_{i}\right)}{d K_{i}}=\frac{\beta}{\beta-1}\left(1+(1-\lambda) \frac{\partial\left(F^{H}\left(K_{i}\right) / f^{H}\left(K_{i}\right)\right)}{\partial K_{i}}+\lambda\left(\frac{Y_{i}^{L}\left(K_{i}\right)}{Y_{i}^{H}\left(K_{i}\right)} \frac{\partial\left(F^{H}\left(K_{i}\right) / f^{H}\left(K_{i}\right)\right)}{\partial K_{i}}+\frac{\partial\left(Y^{L}\left(K_{i}\right) / Y^{H}\left(K_{i}\right)\right)}{\partial K_{i}} \frac{F^{L}\left(K_{i}\right)}{f^{H}\left(K_{i}\right)}\right)\right),
$$

where

$\frac{\partial\left(Y_{i}^{L}\left(K_{i}\right) / Y_{i}^{H}\left(K_{i}\right)\right)}{\partial K_{i}}=(n-1) \frac{\left(1-F^{L}\left(K_{i}\right)\right)^{n-2}}{\left(1-F^{H}\left(K_{i}\right)\right)^{n}}\left[f^{H}\left(K_{i}\right)\left(1-F^{L}\left(K_{i}\right)\right)-f^{L}\left(K_{i}\right)\left(1-F^{H}\left(K_{i}\right)\right)\right]$.

Thus, given $f^{H}\left(K_{i}\right) \geq f^{L}\left(K_{i}\right), \frac{\partial\left(Y_{i}^{L}\left(K_{i}\right) / Y_{i}^{H}\left(K_{i}\right)\right)}{\partial K_{i}} \geq 0$. Under the assumption that $F^{L}\left(K_{i}\right) / f^{H}\left(K_{i}\right)$ increases in $K_{i}$ and $\lambda \leq 0$, we find that $\frac{d S_{i}^{A I}\left(K_{i}\right)}{d K_{i}} \geq 0$. 


\section{A.3 The impact of an increase in the effort cost $\xi$ on the optimal investment strategy}

Differentiation of $S_{i}^{A I}\left(K_{i}\right)$ in equation $(22)$ with respect to $x i$ :

$$
\frac{d S_{i}^{A I}\left(K_{i} ; \xi\right)}{d \xi}=-\frac{\beta}{\beta-1} \frac{d \lambda}{d \xi}\left(\frac{F^{H}\left(K_{i}\right)}{f^{H}\left(K_{i}\right)}-\frac{Y_{i}^{L}\left(K_{i}\right)}{Y_{i}^{H}\left(K_{i}\right)} \frac{F^{L}\left(K_{i}\right)}{f^{H}\left(K_{i}\right)}\right)
$$

The Lagrangian multiplier increases in the effort cost, as

$$
\frac{d \lambda}{d \xi}=s \frac{\beta-1}{\beta^{2}}\left[\int_{\underline{K}}^{\bar{K}}\left(1+\frac{1}{f^{H}\left(K_{i}\right) Y_{i}^{H}\left(K_{i}\right)}\right)\left(Y_{i}^{H}\left(K_{i}\right) F^{H}\left(K_{i}\right)-Y_{i}^{L}\left(K_{i}\right) F^{L}\left(K_{i}\right)\right) d K_{i}\right]^{-1} \geq 0 .
$$

Thus, the sign of $\frac{d S_{i}^{A I}\left(K_{i} ; \xi\right)}{d \xi}$ in $(32)$ depends on the sign of the term inside the parenthesis in (32), as shown in (25).

\section{References}

Antle, R., Bogetoft, P., and Stark, A. W. (2001). "Information systems, incentives and the timing of investments", Journal of Accounting and Public Policy, 20, 267-294.

Baron, D. P. and Myerson, R. B. (1982). "Regulating a monopolist with unknown costs", Econometrica, 50(4), 911-930.

Bjerksund, P. and Ekern, S. (1990). "Managing Investment Opportunities Under Price Uncertainty: From "Last Chance" to "Wait and See" Strategies", Financial Management, Autumn. Reprinted in Real Options and Investment under Uncertainty: Classical Readings and Recent Contributions, E. Schwartz and L. Trigeorgis (eds.), MIT Press, 2001.

Bjerksund, P. and Stensland, G. (2000). "A Self-enforced Dynamic Contract for Processing of Natural Resources", In Brennan, M. J. and Trigeorgis, L. (Eds.), Project Flexibility, Agency, and Competition: New Developments in the Theory and Application of Real Options. Oxford University Press. 
Dixit, A. (1989). "Entry and Exit Decisions under Uncertainty", Journal of Political Economy, $97(3), 620-638$.

Grenadier, S. R. and Wang, N. E. (2005). "Investment Timing, Agency and Information", Journal of Financial Economics, 75(3), 493-533.

Klemperer, P. (1999). "Auction Theory: A Guide to the Literature", Journal of Economic Surveys, 13(3), 227-286. Also reprinted in The Economic Theory of Auctions, P. Klemperer (ed.), Edward Elgar (pub.), Cheltenham, UK, 2000, pp. 3-62, and reprinted in The current State of Economic Science, S. Dahiya (ed.), Vol. 2, 1999, pp. 711-766.

Laffont, J.-J. and Tirole, J. (1987). "Auctioning Incentive Contracts", Journal of Political Economy, 95(5), 921-937.

Laffont, J.-J. and Tirole, J. (1993). A Theory of Incentives in Procurement and Regulation. MIT Press, MIT, Massachusettes.

Mæland, J. (2002). "Valuation of Irreversible Investments and Agency Problems", working paper, forthcoming in Trigeorgis, L. (ed.), Innovation, Organization and Strategy, Cambridge University Press.

Mæland, J. (2005). "Asymmetric Information and Irreversible Investments: An Auction Model", working paper.

McDonald, R. and Siegel, D. (1986). "The value of waiting to invest", Quarterly Journal of Economics, 101, 707-727.

Moel, A. and Tufano, P. (2000). "Bidding for the Antamina Mine", In Brennan, M. J. and Trigeorgis, L. (Eds.), Project Flexibility, Agency, and Competition: New Developments in the Theory and Application of Real Options. Oxford University Press.

Myerson, R. B. (1981). "Optimal auction design", Mathematics of Operations Research, 6(1), $58-73$. 
Riley, J. G. and Samuelson, W. F. (1981). "Optimal Auctions", The American Economic Review, 71 (3), 381-392. 